УДК 159.922.1

\title{
ВЗАИМОСВЯЗЬ ПОИСКА ОЩУЩЕНИЙ С САМООТНОШЕНИЕМ И МОТИВАЦИЕЙ ОДОБРЕНИЯ: ГЕНДЕРНЫЙ АСПЕКТ
}

\author{
Дунайцева Наталья Анатольевна \\ Петраш Юлия Витальевна
}

Статья посвящена исследованию взачмосвязи поиска ощущений с самоотношением и мотивацией одобрения у мужчин и женщин. Проанализированы различные подходы к такой личностной черте, как поиск ощущений и переживаний. Отмечена недостаточность эмпирического материала по данной теме, что обуславливает актуальность и новизну проведенного исследования.

Объектом исследования выступили 111 человек (56 женщин и 55 мужчин) в возрасте от 19 до 73 лет, проживающие в г. Ростове-на-Дону. В исследовании, наряду с гендерным аспектом, также учитывается и фактор наличия или отсутствия детей. Эмпирически выявлены и проанализированы многочисленные взаимосвязи поиска ощущений, самоотношения и мотивации одобрения.

Установлено, что поиск новых ощущений наиболее выражен у мужчин и не зависит от наличия детей. Взаимосвязь поиска ошущений с самоотношением выявлена только у мужчин, поиск ощущений у женщин не связан с самоотношением. Склонность к поиску новых ошущений, авантюрам и рискованному поведению свойственна мужчинам с низким уровнем саморуководства, самопринятия, самопривязанности, самоуважения, аутосимпатии. Исследование также показало, что мотивация одобрения связана с самоотношением у женшин: высокий уровень мотивации одобрения связан с высоким уровнем самоотношения, а именно с такими его аспектами, как: самоуверенность, саморуководство, самопривязанность, самоуважение. Также эмпирически установлено, что мотивация одобрения более выражена у респондентов, имеющих детей, что свидетельствует о стремлении родителей показать себя в социуме с лучшей стороны.

Ключевые слова: поиск ошущений, самоотношение, саморуководство, самопривязанность, самоуважение, самоченность, аутосимпатия, мотивачия одобрения, социальная желательность, гендер.

\section{Введение}

Готовность к поиску ощущений и переживаний можно смело отнести к числу наименее изученных личностных черт. Ученые (Н. М. Щелованов, 
М. Ю. Кистяковская, С. Р. Клонингер), занимавшиеся исследованием данного феномена, подходили к изучению поиска ощущений с разных позиций: наблюдали его развитие в онтогенезе, искали истоки ориентированности личности на поиск новизны в биохимической основе организма, рассматривали его преобразование в процессе эволюции мотивационной сферы человека и т. д. [6, 9, 11, 19, 21, 22, 23]. Согласно биосоциальной модели М. Цукермана (сторонниками которой мы являемся), поиск ощущений у индивида определяется не базальными уровнями дофамина, серотонина, норадреналина, а их реактивностью в ответ на действие стимулов из окружающей среды. Психологически, поиск ощущений определяется как черта личности, которая выражает поиск вариативных, новых, сложных и интенсивных ощущений и переживаний, готовность к риску $[24,25]$. Из анализа точек зрения различных авторов, пытавшихся теоретически решить проблему поиска ощущений, явствует, что для решения этой проблемы им не хватает конкретного психологического материала, получаемого путем соответствующих исследований $[1,4,16]$.

Проведенный нами анализ специальной психологической литературы не обнаружил подобных научных изысканий, что составляет новизну проведенного нами исследования. Кроме того, новизна данной работы заключается в изучении гендерного аспекта предмета исследования [2, 3]. Следует отметить, что в данной работе, наряду с другими исследователями $[5,8,20]$, мы придерживаемся биодетерминистских позиций, связывая социальные и психологические отличия мужчин и женщин с их врожденными половыми особенностями, и употребляем понятия «гендер» и «пол» как синонимичные.

Целью нашего исследования является изучение взаимосвязи поиска ощущений с самоотношением и мотивацией одобрения в гендерном аспекте.

Исходя из вышеизложенного, мы предположили, что: 1) поиск ощущений у мужчин и женщин имеет существенные различия; 2) существуют различия во взаимосвязях между поиском ощущений и самоотношением у мужчин и женщин; 3) существуют различия во взаимосвязях между поиском ощущений и мотивацией одобрения у мужчин и женщин.

\section{Методы и методики исследования}

Выборка исследования составила 111 человек. Из них - 56 женщин и 55 мужчин. В исследовании принимали участие только взрослые респонденты возрастом от 19 до 73 лет. Исследование проводилось в 3 этапа: 1) для диагностики личностной черты «готовность к поиску ощущений» применялась шкала поиска ощущений М. Цукермана [18]; 2) применялся многомерный опросник исследования самоотношения С. Р. Пантилеева (МИС - методика исследования самоотношения) [14]; 3) для диагностики мотивации одобрения 
использовался тест мотивации одобрения (социальной желательности), разработанный Д. Марлоу и Д. Крауном [12].

Достоверность исследования обеспечена использованием параметрических и непараметрических методов математической статистики. В качестве первого типа методов математической статистики использован метод подсчета величин математического среднего и стандартного отклонения, метод сравнения двух выборок с использованием параметрического t-критерия Стьюдента. Из числа непараметрических представлены: метод корреляционного анализа по критериям Пирсона, Спирмена, Шапиро-Уилка, U-критерию Манна-Уитни, критерию хи-квадрат, а также - метод процентного анализа данных (с использованием программы SPSS 10.0).

\section{Результаты}

Перейдем к анализу полученных результатов. Проанализируем основной показатель нашего исследования - поиск ощущений.

Результаты вычислений опросника М. Цукермана, представленные в таблице 1, показывают, что мужчины более склонны к поиску ощущений, у них выше склонность к необдуманным поступкам и авантюрам.

Таблича 1.

Уровень поиска ощущений у мужчин и женщин

\begin{tabular}{|l|c|c|c|c|}
\hline & Женщины & Мужчины & $\boldsymbol{U}$ & $\boldsymbol{p}$ \\
\hline Поиск ощущений & 7.37 & 8.69 & 924 & 0.032 \\
\hline
\end{tabular}

В нашем исследовании учитывается еще один показатель: наличие или отсутствие детей. Результаты расчетов в таблице 2 показывают, что респонденты с детьми и без детей не различаются по уровню стремления к новым ощущениям. В связи с этим мы констатируем, что поиск ощущений имеет гендерный аспект, который проявляется в повышенной склонности мужчин к поиску ощущений.

Таблица 2.

\section{Уровень поиска ощущений у респондентов с детьми и без детей}

\begin{tabular}{|l|c|c|c|c|}
\hline & Eсть детu & Hem дemeŭ & $\boldsymbol{U}$ & $\boldsymbol{p}$ \\
\hline Поиск ощущений & 7.16 & 8.13 & 1149.5 & 0.073 \\
\hline
\end{tabular}

Результаты опросника исследования самоотношения С. Р. Пантилеева у мужчин и женщин представлены в таблице 3. Сырые баллы первичных шкал данного теста переводились в стены согласно нормам, предоставленным 
авторами $[14,15]$. В шкале стенов средним является значение 5,5, стандартным - отклонение 2, соответственно, интервал нормы лежит в пределах 3,5-7,5 стенов.

Таблица 3.

Параметры самоотношения мужчин и женщин (по первичным шкалам)

\begin{tabular}{|c|c|c|c|c|}
\hline & Женщины & Мужчины & $\boldsymbol{U}$ & $\boldsymbol{p}$ \\
\hline Внутренняя честность & 6.27 & 5.91 & 1422 & 0.242 \\
\hline Самоуверенность & 6.24 & 6.16 & 1324 & 0.605 \\
\hline Саморуководство & 6.44 & 6.16 & 1371.5 & 0.408 \\
\hline Зеркальное Я & 6.45 & 6.06 & 1460 & 0.154 \\
\hline Самоценность & 7.38 & 7.19 & 1328 & 0.593 \\
\hline Самопринятие & 6.54 & 7.09 & 1016 & 0.119 \\
\hline Самопривязанность & 5.67 & 5.5 & 1337.5 & 0.551 \\
\hline $\begin{array}{c}\text { Внутренняя } \\
\text { конфликтность }\end{array}$ & 4.33 & 4.22 & 1313.5 & 0.663 \\
\hline Самообвинение & 4.31 & 4.41 & 1243.5 & 0.979 \\
\hline
\end{tabular}

Статистический критерий не показал значимых различий в группе мужчин и женщин по первичным шкалам самоотношения (таблица 3).

Вторичные шкалы опросника исследования самоотношения были выведены авторами в результате факторного анализа первичных шкал. В связи с тем, что авторы не предоставляют норм для вторичных шкал своего теста, мы перевели их в процентили, с целью стандартизировать их значения и привести к единой системе измерения $[7,14,17]$. В шкале процентилей средним значениям соответствует 50 баллов, диапазон нормы лежит в пределах 2-3 квартилей (25-75 баллов).

Таблича 4.

Параметры самоотношения в группе мужчин и женщин (по вторичным шкалам)

\begin{tabular}{|c|c|c|c|c|}
\hline Шкалы & Женщины & Мужчины & $\boldsymbol{U}$ & $\boldsymbol{p}$ \\
\hline Самоуважение & 54.96 & 47.5 & 1437 & 0.214 \\
\hline Аутосимпатия & 53.82 & 52.19 & 1279 & 0.841 \\
\hline $\begin{array}{c}\text { Внутренняя } \\
\text { неустроенность }\end{array}$ & 54 & 51.44 & 1316 & 0.656 \\
\hline
\end{tabular}


Показатели средних значений по вторичным шкалам опросника также не различаются, что подтверждается незначимыми критериями (таблица 4). Таким образом, мы можем сделать вывод, что самоотношение не имеет различий у мужчин и женщин. В нашем исследовании учитывается еще один показатель: наличие или отсутствие детей. Результаты средних значений представлены в таблице 5 .

Таблица 5.

Параметры самоотношения у респондентов, имеющих и не имеющих детей

\begin{tabular}{|c|c|c|c|c|}
\hline & Есть детu & Нет детей & $\boldsymbol{U}$ & $\boldsymbol{p}$ \\
\hline Внутренняя честность & 6.21 & 6.13 & 1455.5 & 0.927 \\
\hline Самоуверенность & 6.12 & 6.28 & 1310 & 0.407 \\
\hline Саморуководство & 6.72 & 6.12 & 1697.5 & 0.108 \\
\hline Зеркальное Я & 6.4 & 6.3 & 1461 & 0.9 \\
\hline Самоценность & 6.81 & 7.66 & 1022 & 0.009 \\
\hline Самопринятие & 6.91 & 6.57 & 1589 & 0.354 \\
\hline Самопривязанность & 6.33 & 5.16 & 1945 & 0.002 \\
\hline $\begin{array}{c}\text { Внутренняя } \\
\text { конфликтность }\end{array}$ & 4.19 & 4.37 & 1266.5 & 0.278 \\
\hline Самообвинение & 4.3 & 4.36 & 1437.5 & 0.988 \\
\hline
\end{tabular}

Эмпирически выявлено, что самоценность взрослых, не имеющих детей, значимо выше ( $U=1022 ; p=0,009)$, причем значение данной шкалы выходит за рамки нормы в сторону высоких баллов. Это характеризует взрослых без детей, как имеющих большую заинтересованность в собственном Я, любящих себя, ощущающих ценность собственной личности и одновременно предполагаемую ценность своего Я для других. Самопривязанность находится в пределах нормы в обеих выборках, однако в выборке взрослых с детьми она все же несколько выше $(U=1945 ; p=0,002)$, что говорит о несколько большей ригидности их Я-концепции, привязанности, нежелании меняться на фоне общего положительного отношения к себе. Данные переживания часто сопровождаются привязанностью к неадекватному Я-образу. Далее были проанализированы вторичные шкалы опросника самоотношения (таблица 6). 
Таблица 6.

Параметры самоотношения у респондентов с детьми и без детей (по вторичным шкалам)

\begin{tabular}{|c|c|c|c|c|}
\hline & Ecmь детu & Hem детей & $\boldsymbol{U}$ & $\boldsymbol{p}$ \\
\hline Самоуважение & 54 & 52.01 & 1519.5 & 0.63 \\
\hline Аутосимпатия & 55.4 & 52.03 & 1547.5 & 0.513 \\
\hline $\begin{array}{c}\text { Внутренняя } \\
\text { неустроенность }\end{array}$ & 50.33 & 55.13 & 1305.5 & 0.409 \\
\hline
\end{tabular}

Как видно из таблицы 6, значимых различий не наблюдается, и самоотношение не зависит от наличия ребенка. Таким образом, самоотношение фактически не имеет различий у мужчин и женщин и имеет минимальные различия у взрослых, имеющих и не имеющих детей. В связи с этим, имеет смысл проанализировать общий профиль самоотношения без учета дополнительных факторов пола и наличия детей. Для респондентов, участвовавших в исследовании, наиболее свойственна самоценность, что отражает их заинтересованность в собственном Я, любовь к себе, ощущение ценности собственной личности и одновременно предполагаемую ценность своего Я для других. Менее всего респондентам свойственны внутренняя конфликтность и склонность к самообвинению, что позволяет охарактеризовать их как не переживающих чрезмерные внутренние конфликты и отсутствие чувства вины как характерного переживания собственного Я.

Диагностика мотивации одобрения, иначе называемая шкалой социальной желательности, показала, что мужчины и женщины имеют равную степень выраженности социальной желательности ( $\mathrm{t}=0,67 ; \mathrm{p}=0,5)$. Также нами были проверены различия в зависимости от наличия ребенка (таблица 7).

Таблича 7.

\section{Сравнение выборок респондентов с детьми и без детей} по уровню мотивации одобрения

\begin{tabular}{|c|c|c|c|c|}
\hline & Eсть детu & Hem детей & $\boldsymbol{U}$ & $\boldsymbol{p}$ \\
\hline $\begin{array}{c}\text { Мотивация } \\
\text { одобрения }\end{array}$ & 9.98 & 8.51 & 1849.5 & 0.012 \\
\hline
\end{tabular}

Расчеты показали, что у респондентов, имеющих детей, социальная желательность выше, таким образом, они стремятся в большей мере, чем респонденты без детей, показать себя с лучшей стороны. 
Далее были выявлены взаимосвязи стремления к поиску ощущений и самоотношения у всей выборки - и у мужчин и женщин в отдельности. С этой целью был рассчитан ранговый коэффициент корреляции Спирмена (таблица 8).

Таблица 8.

\section{Взаимосвязь поиска ощущений с особенностями самоотношения}

\begin{tabular}{|c|c|c|c|}
\hline & \multicolumn{3}{|c|}{ Потребность в новых ощущениях } \\
\hline & Bce & Мужчины & Женщины \\
\hline $\begin{array}{l}\text { Внутренняя } \\
\text { честность }\end{array}$ & -0.11 & -0.25 & -0.04 \\
\hline Самоуверенность & 0.03 & -0.22 & 0.16 \\
\hline Саморуководство & -0.23 & -0.38 & -0.14 \\
\hline Зеркальное Я & -0.06 & -0.25 & 0.05 \\
\hline Самоценность & -0.06 & -0.30 & 0.10 \\
\hline Самопринятие & -0.07 & -0.37 & 0.02 \\
\hline Самопривязанность & -0.26 & -0.40 & -0.19 \\
\hline $\begin{array}{c}\text { Внутренняя } \\
\text { конфликтность }\end{array}$ & -0.12 & -0.03 & -0.15 \\
\hline Самообвинение & 0.01 & 0.18 & -0.07 \\
\hline Самоуважение & -0.14 & -0.36 & -0.02 \\
\hline Аутосимпатия & -0.22 & -0.47 & -0.09 \\
\hline $\begin{array}{c}\text { Внутренняя } \\
\text { неустроенность }\end{array}$ & -0.08 & 0.04 & -0.13 \\
\hline
\end{tabular}

Отметим, что поиск ощущений у женщин не связан с самоотношением. Судя по всему, особенности самопринятия, личностные конфликты, доверие к себе и т. д. не подвигают женщин искать новые впечатления. Поиск ощущений связан с низким саморуководством во всей выборке ( $r=-0,23 ; p \leq 0.05)$, однако анализ с учетом пола показывает, что эта взаимосвязь существует только за счет мужской выборки ( $r=-0,38 ; p \leq 0.05)$. Выявленная закономерность свидетельствует о том, что чем хуже саморегуляция, и чем больше Я человека зависит от обстоятельств, тем больше мужчины стремятся к новым переживаниям и впечатлениям, больше склонны к авантюрам. То же касается и связи стремления к поиску ощущений с самопринятием у мужчин ( $r=-0,37 ; p \leq 0.05)$. Мужчины, которыми движет внутреннее противоречие, которые не принимают себя такими, какие они есть - склонны к поиску ощущений. У женщин эта закономерность отсутствует. Для всей выборки характерна отрицательная взаимосвязь самопривязанности и стремления к новым ощущениям ( $r=-0,26 ; p \leq 0.05)$, однако она существует только за счет мужской выборки. Мужчины с низкой самопривязанностью также 
более склонны к поиску ощущений ( $r=-0,40 ; p \leq 0.05)$. Судя по всему, желание что-либо изменить в себе, неудовлетворенность собой повышают степень стремления к новым впечатлениям. Мы предполагаем, что эта закономерность отражает особенности поиска себя, своей сущности мужчинами. Женщинам эта закономерность не свойственна. Низкий уровень самоуважения также заставляет только мужчин искать новые ощущения ( $r=-0,36 ; p \leq 0.05)$. Соответственно, те мужчины, которые низко оценивают себя с точки зрения морали, социально-нормативных критериев, наиболее склонны к поиску ощущений, авантюрам, рискованному поведению. Женщинам это не свойственно. Мужчины с низкой аутосимпатией также склонны к поиску ощущений ( $r=-0,47 ; p \leq 0.05)$, причем эта закономерность наблюдается для всей выборки, но существует только за счет мужчин. Женщинам это также не свойственно.

В нашем исследовании рассматривается также взаимосвязь между поиском ощущений и мотивацией одобрения у мужчин и женщин. Как показали результаты проведенного корреляционного анализа, мотивация одобрения не связана со стремлением к поиску ощущений. Отметим также, что с возрастом поиск ощущений у женщин падает $(r=-0,31 ; p \leq 0.05)$, что не характерно для мужчин, у которых эта связь проявляется независимо от возраста.

Кроме выявленных выше закономерностей, мы имеем возможность проанализировать связь социальной желательности с самоотношением. Были получены значимые положительные корреляции внутренней честности с мотивацией одобрения, причем эта закономерность характерна для всей выборки ( $r=0,45 ; p \leq 0.05)$, для выборки мужчин $(r=0,53 ; p \leq 0.05)$ и для выборки женщин ( $r=0,41 ; p \leq 0.05)$. Только женщинам с высокой мотивацией одобрения свойственны самоуверенность, т. е. высокое самомнение, и отсутствие напряженности ( $r=0,36 ; p \leq 0.05)$. Самоуверенные женщины склонны переоценивать свои возможности, показывать себя только с лучшей стороны. Для мужчин нет четкой закономерности между этими явлениями. Сочетание высокого саморуководства и высокой мотивации одобрения также свойственно только женщинам ( $r=0,46 ; p \leq 0.05)$. Таким образом, чем сильнее у женщин способность руководствоваться только собственным мнением, тем более им свойственно показывать себя с лучшей стороны. Самопривязанность положительно взаимосвязана с мотивацией одобрения у женщин ( $r=0,48 ; p \leq 0.05)$. Согласно интерпретации авторов, самопривязанность часто проявляется в привязанности к неадекватному образу собственного Я, ригидности, и вполне закономерно высокое стремление таких женщин к социальному одобрению $[14,15]$. Внутренняя конфликтность и мотивация одобрения отрицательно связаны у женщин ( $r=-0,38 ; \mathrm{p} \leq 0.05)$. Таким образом, у женщин непринятие себя, сомнение в собственных силах совпадает 
с более реалистичным представлением о себе и нежеланием показывать себя только с лучшей стороны. Самоуважение связано с высокой мотивацией одобрения у всех респондентов ( $r=0,49 ; p \leq 0.05)$, у мужчин $(r=0,48 ; p \leq 0.05)$ и у женщин $(r=0,51 ; p \leq 0.05)$. Таким образом, чем выше респондент оценивает себя с позиций общественной морали, уважает собственное Я, тем с лучшей стороны он стремится себя показать. Аутосимпатия, т. е. положительное эмоциональное отношение к себе, положительно взаимосвязана с мотивацией одобрения только у женщин ( $r=0,28$; $p \leq 0.05)$. Внутренняя неустроенность и потребность в психологической поддержке совпадают с низкой мотивацией одобрения у женщин ( $r=-0,34 ; p \leq 0.05)$.

\section{Выводы}

На основе полученных результатов можно сделать следующие выводы:

1. Поиск ощущений выше у мужчин, что подтверждает нашу первую гипотезу.

2. Анализ взаимосвязей поиска ощущений и самоотношения выявил множество закономерностей. В первую очередь, необходимо отметить, что поиск ощущений связан с самоотношением только у мужчин. В частности, результаты исследования позволяют утверждать, что высокие саморуководство, самопривязанность, самоуважение и аутосимпатия характерны для мужчин с низким уровнем поиска ощущений, что частично подтверждает нашу вторую гипотезу. У женщин действуют другие закономерности, которые требуют дальнейших исследований.

3. Анализ взаимосвязи поиска ощущений и мотивации одобрения не выявил гендерных различий, что не подтверждает нашу третью гипотезу.

4. Нами были получены и другие взаимосвязи (которые не были отражены в гипотезах исследования), в частности между самоотношением и мотивацией одобрения. Самоотношение связано с мотивацией одобрения в основном у женщин. Можно утверждать, что чем выше самоотношение, а именно - самоуверенность, саморуководство, самопривязанность, самоуважение и аутосимпатия, тем больше женщины склонны к социальной желательности. Для мужчин характерна взаимосвязь самоуважения и мотивации одобрения.

5. Так как в нашем исследовании учитывался фактор наличия или отсутствия детей, считаем необходимым отметить, что поиск ощущений у мужчин и женщин не зависит от наличия детей. Особенностями самоотношения респондентов, не имеющих ребенка, являются заинтересованность в собственном Я, любовь к себе, ощущение ценности собственной личности и одновременно предполагаемой ценности своего Я для других. При этом у респондентов с детьми выше самопривязанность. Мотивация 
одобрения респондентов зависит от наличия ребенка. В частности, было обнаружено, что родители более склонны к тому, чтобы показывать себя с лучшей стороны.

Таким образом, в данной работе рассмотрена взаимосвязь поиска ощущений с самоотношением и мотивацией одобрения в гендерном аспекте. Понимание механизма поиска ощущений, их возникновения и развития, а также проявления гендерных особенностей помогло бы решить целый ряд задач личностного характера, способствовало бы пониманию процесса эволюции супружеских взаимоотношений, сыграло бы важную роль в решении проблем родительской сферы.

\section{Литература}

1. Абульханова-Славская К. А. Стратегия жизни. - М., 1991. - 298 с.

2. Архиреева T.В. Родительские позиции как условие развития отношения к себе ребенка младшего школьного возраста: автореф. дисс. ... канд. психол. наук. - М., 1990. - 19 с.

3. Белогай К. Н. Некоторые аспекты изучения гендерных различий в структуре родительского отношения // Перинатальная психология и психология родительства. - 2004. - № 2. - С. 31-49.

4. Бурлачук Л. Ф., Морозов С. М. Словарь-справочник по психодиагностике. - СПб., 2001. - 528 с.

5. Грейдина Н. Л. Гендерная специфика коммуникации // Антропоцентрический подход к исследованию социума: лингвистические, социолингвистические и культурологические аспекты: материалы науч.-практ. телеконф., посвященной Международному году языков и 10-летию гуманитарного отделения ИГХТУ. - Иваново, 2002. - С. 5-14.

6. Джеймс У. Психология. - М.: Педагогика, 1991. - 368 с.

7. Калинин С. И. Компьютерная обработка данных для психологов. - СПб.: Речь, 2002. - 136 с.

8. Кирилина А. В. Гендер: Лингвистические аспекты. - М.: Изд-во Института социологии РАН, 1999 - 180 с.

9. Кистяковская М. Ю. О стимулах, вызывающих положительные эмоции у ребенка первых месяцев жизни // Вопр. психопатологии. - 1965. № 2. - С. 129-140.

10. Луковицкая Е. Г. Социально-психологическое значение толерантности к неопределенности: автореф. дисс. ... канд. психол. наук. - СПб., 1998. - 18 c.

11. Лурия А. Р. Лекции по общей психологии. - СПб., 2013. - 320 с.

12. Методика диагностики самооценки мотивации одобрения (Шкала лжи) Д. Марлоу и Д. Крауна // Практическая психодиагностика. Методики 
и тесты. Учебное пособие. Ред. и сост. Д. Я. Райгородский. - Самара, 2001. - С. 635-636.

13. Панкратов В. Н. Саморегуляция психического здоровья: практическое руководство. - М.: Изд-во Ин-та психотерапии, 2001. - 352 с.

14. Пантилеев С. Р. Методика исследования самоотношения. - М., 1993. - 32 с.

15. Пантилеев С. Р. Самоотношение как эмоционально-оценочная система. - М., 1991. - 338 с.

16. Практикум по общей, экспериментальной и прикладной психологии / Под ред. А. А. Крылова, С. А. Маничева. - СПб.: Питер, 2006. - 560 с.

17. Сидоренко Е. В. Методы математической обработки в психологии. - СПб., 2007. - 350 c.

18. Шкала поиска ощущений (М. Цукерман) // Альманах психологических тестов. - М., 1995. - С. 187-189.

19. Щелованов Н. М., Аксарина Н. М. Воспитание детей раннего возраста в детских учреждениях. - М., 1955. - 302 с.

20. Ashmore R. D. Sex, gender, and the individual // Handbook of personality: Theory and research / Ed. by L. A. Pervin. - N. Y.: Guilford Press, 1990.

21. Cloninger C. R. A systematic method for clinical description and classification of personality variants: A proposal // Arch. Gen. Psychiatry. - 1987.

22. Cloninger C. R., Svrakic D. M. Integrative psychobiological approach to psychiatric assessment and treatment // Psychiatry. - 1997.

23. Cloninger $C$. $R$. et al. Anxiety proneness linked to epistatic loci in genome scan of human personality traits // Am. J. Med. Genet. - 1998.

24. Zuckerman M. Behavioral expressions and psychological bases of sensation seeking. - N. Y.: Cambridge University Press, 1994.

25. Zuckerman $M$. Sensation seeking. Sensation seeking and risky behavior. Washington, DC, US: American Psychological Association, 2007. - pp. 3-49. 